\title{
Optimization of Electroless Ni-P Coatings Based on Surface Roughness
}

\author{
Prasanta Sahoo \\ Department of Mechanical Engineering, Jadavpur University \\ Kolkata 700032, India \\ psahoo@vsnl.net
}

( Manuscript received 4 December 2007; accepted 4 January 2008; published 31 January 2008 )

\begin{abstract}
This paper presents an experimental study of roughness characteristics of electroless Ni-P coatings and optimization of coating process parameters based on $L_{27}$ Taguchi orthogonal design. Experiments are carried out by utilizing the combination of three process parameters, viz., bath temperature, concentration of nickel source solution and concentration of reducing agent. It is observed that concentration of nickel source solution has got the most significant influence in controlling roughness characteristics of electroless Ni-P coating. The optimum combination of process parameters for minimum roughness is obtained from the analysis. The surface morphology and composition of coatings are also studied with the help of scanning electron microscopy, energy dispersed X-ray analysis and X-ray diffraction analysis.
\end{abstract}

Keywords: electroless Ni-P coating, surface roughness, Taguchi analysis

\section{Introduction}

Electroless Ni-P (EN) coatings, first developed by Brenner and Riddell ${ }^{1}$, have found extensive use in mechanical, chemical and electronic industries ${ }^{2)}$ due to their excellent mechanical, physical, electrical, corrosion, and tribological properties. Another advantage is that EN coatings can be applied to a variety of substrate materials and plated uniformly on intricate part geometries. Electroless Ni-P coating is an autocatalytic deposition of a Ni-P alloy from an aqueous solution onto a substrate without the application of electric current that distinguishes it from the conventional electroplating processes. The electroless bath typically comprises an aqueous solution of metal ions, complexing agents, reducing agents and stabilizers, operating in a specific metal ion concentration, temperature and $\mathrm{pH}$ ranges. The deposition rate, properties of coated components and the structural behavior of deposits mainly depend upon the plating bath constituents/conditions such as the type and concentrations of the reducing agent, stabilizer, used $\mathrm{pH}$ and the temperature of the bath etc. The properties and microstructures of EN coatings depend on the amount of phosphorous alloyed in the $\operatorname{deposit}^{3-7)}$. The post-deposition heat treatment influences the properties by altering the microstructures ${ }^{5-8)}$. The mechanical and tribological properties of these coatings can further be improved by the incorporation of hard particles ${ }^{8,9)}$ and dry lubricants ${ }^{9-11)}$. Friction and wear being important properties of EN coatings, these have also been the focus of attention of a number of researchers ${ }^{12-17)}$ over the years.

Surface roughness has large impact on the mechanical properties like fatigue behavior, corrosion resistance, creep life etc. It also affects other functional attributes of machine components like friction, wear, light reflection, heat transmission, lubrication, electrical conductivity etc. As a result, there is a need for research developments in modeling surface roughness and optimization of the controlling parameters to obtain a surface finish of desired level. Despite a good number of studies on EN coatings particularly on tribological properties, it is seen from an extensive literature review that no report is available on optimization of the process parameters of EN coating to have optimum roughness characteristics. The present study deals with the application of Taguchi method to determine the suitable coating process parameters for optimum surface roughness in EN coatings. The surface morphology and composition of EN coatings are studied with the help of scanning electron microscopy, energy dispersed X-ray analysis and $\mathrm{X}$-ray diffraction analysis.

\section{Taguchi method}

Taguchi technique ${ }^{18,19)}$ is a powerful tool for design of high quality systems based on orthogonal array experiments that provide much reduced variance for the experiments with an optimum setting of process control parameters. The orthogonal array (OA) requires a set of well balanced (minimum experimental runs) experiments. Taguchi's method uses a statistical measure of 
performance called signal-to-noise ratios $(\mathrm{S} / \mathrm{N})$, which are logarithmic functions of desired output to serve as objective functions for optimization. Three categories of $\mathrm{S} / \mathrm{N}$ ratios are used: lower-the-better (LB), higher-the-better (HB) and nominal-the-best (NB). The parameter level combination that maximizes the appropriate $\mathrm{S} / \mathrm{N}$ ratio is the optimal setting. For the case of minimization of surface roughness, LB characteristic needs to be used. Furthermore, a statistical analysis of variance $(A N O V A)^{20)}$ is performed to find which process parameters are statistically significant. With the $\mathrm{S} / \mathrm{N}$ ratio and ANOVA analyses, the optimal combination of the process parameters can be predicted. Finally, a confirmation experiment is conducted to verify the optimal process parameters obtained from the parameter design.

\section{Experimental details}

\subsection{Coating deposition}

Mild steel (AISI 1040) specimens of size $20 \mathrm{~mm} \times 20$ $\mathrm{mm} \times 8 \mathrm{~mm}$ are used as the substrate material for the deposition of the electroless Ni-P coating. Square shaped specimens are prepared very carefully for the deposition of the electroless Ni-P coating. Shaping, parting and milling processes are used accordingly for the preparation of the samples. The samples are then subjected to surface grinding process. The samples are mechanically cleaned from foreign matter and corrosion products. After that surfaces of the mild steel specimens are cleaned using distilled water. The specimens, after thorough cleaning are given a pickling treatment with dilute $(50 \%)$ hydrochloric acid for one minute. Subsequently, they are rinsed in distilled water followed by methanol cleaning prior to coating. The bath composition and operating conditions for electroless $\mathrm{Ni}-\mathrm{P}$ coating are selected after several experiments and proper ranges of the parameters are chosen accordingly. Three most important parameters are varied and others are kept constant for coating deposition. Table 1 indicates the electroless bath composition and operating conditions used for the deposition of electroless nickel phosphorus coating. EN deposition is carried out using nickel chloride and nickel sulphate as the source of nickel, sodium hypophosphite as the reducing agent and sodium succinate as the stabilizer. The concentration of stabilizer used in baths is kept fixed. The $\mathrm{pH}$ value of the bath was maintained at a fixed value by adding required quantity of dilute hydrochloric acid. The cleaned samples are activated in palladium chloride at $55^{\circ} \mathrm{C}$ temperature and placed in the bath for deposition for 2 hours. Deposition time is kept constant for each and every specimen so that the coating thickness remains approximately constant and the average coating thickness is found to be around $35 \mu \mathrm{m}$. After the deposition the samples are taken out of the electroless nickel bath and washed in distilled water. Further it has been reported in the literature that annealing greatly influences the tribological properties of EN coatings. Thus the samples are heat treated in a box furnace (annealed at $400^{\circ} \mathrm{C}$ for 1 hour) separately.

Table 1 Electroless bath composition and operating conditions

\begin{tabular}{|l|c|c|c|}
\hline \multicolumn{2}{|c|}{ Bath Composition } & \multicolumn{2}{c|}{ Operating Conditions } \\
\hline $\begin{array}{l}\text { Nickel Sulphate } \\
\text { \& Nickel }\end{array}$ & $30-50$ & $\mathrm{pH}$ & 4.5 \\
Chloride (g/l) & $10-24$ & $\begin{array}{c}\text { Deposition } \\
\text { Temp. }\left({ }^{\circ} \mathrm{C}\right)\end{array}$ & $80-90$ \\
\hline $\begin{array}{l}\text { Sodium } \\
\begin{array}{l}\text { Hypophosphite } \\
(\mathrm{g} / \mathrm{l})\end{array}\end{array}$ & 12 & Bath vol. $(\mathrm{ml})$ & 175 \\
\hline $\begin{array}{l}\text { Sodium } \\
\text { Succinate }(\mathrm{g} / \mathrm{l})\end{array}$ & & & 2 \\
\hline
\end{tabular}

It is important to note here that the present study does not consider substrate roughness as an input variable. Thus it is essential that all samples after different stages of processing and prior to coating should have same roughness. But this is extremely difficult to achieve. Thus large numbers of samples are prepared and after all the processing prior to coating these are subjected to roughness evaluation (centre line average, $R_{a}$ ). Only those specimens that show insignificant variation (less than $0.1 \%$ ) in roughness are used for coating deposition.

\subsection{Design factors}

There are a large number of factors that can be considered for control of EN coatings, viz., bath temperature, concentration of reducing agent, concentration of source of nickel, concentration of stabilizer, $\mathrm{pH}$ of solution, substrate roughness, annealing temperature etc. However, consideration of all the factors in a single study is very difficult as it will make the size of the design matrix very large. Also the interactions of so many factors when taken into consideration will make the analysis further complicated.

Table 2 Design factors and their levels

\begin{tabular}{|c|c|c|c|c|}
\hline Design factors & \multirow{2}{*}{ Unit } & \multicolumn{3}{|c|}{ Levels } \\
\cline { 3 - 5 } & & 1 & 2 & 3 \\
\hline $\mathrm{A}$ & ${ }^{\circ} \mathrm{C}$ & 80 & $85^{\mathrm{a}}$ & 90 \\
\hline $\mathrm{B}$ & $\mathrm{g} / 1$ & 10 & $17^{\mathrm{a}}$ & 24 \\
\hline $\mathrm{C}$ & $\mathrm{g} / 1$ & 30 & $40^{\mathrm{a}}$ & 50 \\
\hline
\end{tabular}

a: initial coating condition

The review of literature shows that the following three parameters are the most widespread among the researchers to control the EN coating deposition: (A) bath temperature, (B) concentration of reducing agent (sodium hypophosphite), (C) concentration of source of nickel (nickel chloride and nickel sulphate solution). Thus these three factors are considered as main design factors along with their interactions in the present study. Table 2 shows the design factors along with their levels. 
Table $3 L_{27}$ orthogonal array with design factors and interactions assigned along with experimental results

\begin{tabular}{|l|l|l|l|l|l|l|l|l|l|l|l|l|l|l|l|}
\hline & \multicolumn{10}{|c|}{ Column Numbers } \\
\hline $\begin{array}{l}\text { Trial } \\
\text { No }\end{array}$ & $\begin{array}{l}1 \\
(\mathrm{~A})\end{array}$ & $\begin{array}{l}2 \\
(\mathrm{~B})\end{array}$ & $\begin{array}{l}\mathrm{A} \times \mathrm{B}) \\
(\mathrm{A} \times \mathrm{B})\end{array}$ & $\begin{array}{l}5 \\
(\mathrm{C})\end{array}$ & $\begin{array}{l}(\mathrm{A} \times \mathrm{C}) \\
(\end{array}$ & $\begin{array}{l}7 \\
(\mathrm{~A} \times \mathrm{C})\end{array}$ & $\begin{array}{l}8 \\
(\mathrm{~B} \times \mathrm{C})\end{array}$ & $\begin{array}{l}9 \\
-\end{array}$ & $\begin{array}{l}10 \\
-\end{array}$ & $\begin{array}{l}11 \\
(\mathrm{~B} \times \mathrm{C})\end{array}$ & $\begin{array}{l}12 \\
-\end{array}$ & $\begin{array}{l}13 \\
-\end{array}$ & $R_{a}$ & $\begin{array}{c}\mathrm{S} / \mathrm{N} \\
\text { Ratios }\end{array}$ \\
\hline 2 & 1 & 1 & 1 & 1 & 1 & 1 & 1 & 1 & 1 & 1 & 1 & 1 & 1 & 0.404 & 7.8616 \\
\hline 3 & 1 & 1 & 1 & 1 & 2 & 2 & 2 & 2 & 2 & 2 & 2 & 2 & 2 & 0.442 & 7.0817 \\
\hline 4 & 1 & 2 & 2 & 2 & 1 & 1 & 1 & 2 & 2 & 2 & 3 & 3 & 3 & 0.309 & 10.1924 \\
\hline 5 & 1 & 2 & 2 & 2 & 2 & 2 & 2 & 3 & 3 & 3 & 1 & 1 & 1 & 0.446 & 7.0133 \\
\hline 6 & 1 & 2 & 2 & 2 & 3 & 3 & 3 & 1 & 1 & 1 & 2 & 2 & 2 & 0.417 & 7.5973 \\
\hline 7 & 1 & 3 & 3 & 3 & 1 & 1 & 1 & 3 & 3 & 3 & 2 & 2 & 2 & 0.332 & 9.5772 \\
\hline 8 & 1 & 3 & 3 & 3 & 2 & 2 & 2 & 1 & 1 & 1 & 3 & 3 & 3 & 0.334 & 9.5173 \\
\hline 9 & 1 & 3 & 3 & 3 & 3 & 3 & 3 & 2 & 2 & 2 & 1 & 1 & 1 & 0.482 & 6.3391 \\
\hline 10 & 2 & 1 & 2 & 3 & 1 & 2 & 3 & 1 & 2 & 3 & 1 & 2 & 3 & 0.474 & 6.4844 \\
\hline 11 & 2 & 1 & 2 & 3 & 2 & 3 & 1 & 2 & 3 & 1 & 2 & 3 & 1 & 0.665 & 3.5501 \\
\hline 12 & 2 & 1 & 2 & 3 & 3 & 1 & 2 & 3 & 1 & 2 & 3 & 1 & 2 & 0.501 & 6.0067 \\
\hline 13 & 2 & 2 & 3 & 1 & 1 & 2 & 3 & 2 & 3 & 1 & 3 & 1 & 2 & 0.364 & 8.7827 \\
\hline 14 & 2 & 2 & 3 & 1 & 2 & 3 & 1 & 3 & 1 & 2 & 1 & 2 & 3 & 0.419 & 7.5454 \\
\hline 15 & 2 & 2 & 3 & 1 & 3 & 1 & 2 & 1 & 2 & 3 & 2 & 3 & 1 & 0.384 & 8.3066 \\
\hline 16 & 2 & 3 & 1 & 2 & 1 & 2 & 3 & 3 & 1 & 2 & 2 & 3 & 1 & 0.325 & 9.7543 \\
\hline 17 & 2 & 3 & 1 & 2 & 2 & 3 & 1 & 1 & 2 & 3 & 3 & 1 & 2 & 0.508 & 5.8827 \\
\hline 18 & 2 & 3 & 1 & 2 & 3 & 1 & 2 & 2 & 3 & 1 & 1 & 2 & 3 & 0.402 & 7.9263 \\
\hline 19 & 3 & 1 & 3 & 2 & 1 & 3 & 2 & 1 & 3 & 2 & 1 & 3 & 2 & 0.331 & 9.6087 \\
\hline 20 & 3 & 1 & 3 & 2 & 2 & 1 & 3 & 2 & 1 & 3 & 2 & 1 & 3 & 0.353 & 9.0494 \\
\hline 21 & 3 & 1 & 3 & 2 & 3 & 2 & 1 & 3 & 2 & 1 & 3 & 2 & 1 & 0.379 & 8.4318 \\
\hline 22 & 3 & 2 & 1 & 3 & 1 & 3 & 2 & 2 & 1 & 3 & 3 & 2 & 1 & 0.458 & 6.7827 \\
\hline 23 & 3 & 2 & 1 & 3 & 2 & 1 & 3 & 3 & 2 & 1 & 1 & 3 & 2 & 0.408 & 7.7974 \\
\hline 24 & 3 & 2 & 1 & 3 & 3 & 2 & 1 & 1 & 3 & 2 & 2 & 1 & 3 & 0.438 & 7.1745 \\
\hline 25 & 3 & 3 & 2 & 1 & 1 & 3 & 2 & 3 & 2 & 1 & 2 & 1 & 3 & 0.473 & 8.5588 \\
\hline 26 & 3 & 3 & 2 & 1 & 2 & 1 & 3 & 1 & 3 & 2 & 3 & 2 & 1 & 0.458 & 6.7827 \\
\hline 27 & 3 & 3 & 2 & 1 & 3 & 2 & 1 & 2 & 1 & 3 & 1 & 3 & 2 & 0.287 & 10.8348 \\
\hline
\end{tabular}

\subsection{Response variable}

The response variable used to accomplish the present study on surface topography characterization is the centre line average roughness $R_{a}$. The coating process parameters are optimized with an objective to minimize $R_{a}$, i.e. to yield a smoother surface topography.

\subsection{Design of experiment}

Based on Taguchi method, an orthogonal array provides the shortest possible matrix of combinations in which all the parameters are varied to consider their direct effect as well as interactions simultaneously. In the present investigation, an $L_{27}$ orthogonal array which has 27 rows corresponding to the number of tests (26 degrees of freedom) with 13 columns at three levels is chosen. The 1st column is assigned to bath temperature (A), 2nd column is assigned to concentration of reducing agent (sodium hypophosphite) (B), 5th column is assigned to concentration of source of nickel (nickel chloride and nickel sulphate) (C) and the remaining columns are assigned to the two-way interactions of factors. Table 3 shows the orthogonal array with design factors and their interactions assigned.

\subsection{Roughness measurement}

Roughness measurement was done using a stylus-type profilometer, Talysurf (Taylor Hobson, Surtronic 3+). The profilometer was set to a cut-off length of $0.8 \mathrm{~mm}$, Gaussian filter and $4 \mathrm{~mm}$ evaluation length.

3.6. Surface morphology and composition study

Surface morphology study of the EN coatings is done by scanning electron microscopy (SEM) (JEOL, JSM-6360). Energy dispersive X-ray analysis (EDX) (Inca, Oxford) is done in conjunction with SEM to study the composition of the EN coatings in terms of the percentages of nickel and phosphorous in the coatings before and after heat treatment. An X-ray diffraction (XRD) analyzer (Rigaku, Miniflex) is used for identification of compounds in the EN coatings both before and after heat treatment.

\section{Results and discussion}

4.1. Analysis of signal to noise ratio

The traditional method of calculating the desirable factor levels is to look at the simple averages of the 
results. But it does not capture the variability of the results within a trial condition. That's why the signal to noise ratio analysis is done here with $R_{a}$ as the performance index. The $\mathrm{S} / \mathrm{N}$ ratio for $R_{a}$ is calculated using LB (lower-the-better) criterion and the same is given by

$$
S / N=-10 \log \left(\sum y^{2} / n\right)
$$

where $y$ is the observed data and $n$ is the number of observations. Table 3 also shows the experimental results for $R_{a}$ and the corresponding $\mathrm{S} / \mathrm{N}$ ratio. Since the experimental design is orthogonal, it is then possible to separate out the effect of each coating parameter at different levels. For example, the mean $\mathrm{S} / \mathrm{N}$ ratio for factor $A$ at levels 1,2 and 3 can be calculated by averaging the $\mathrm{S} / \mathrm{N}$ ratios for the experiments 1-9, 10-18, and $19-27$, respectively. The mean $\mathrm{S} / \mathrm{N}$ ratio for each level of the other factors can be computed in the similar manner. The mean $\mathrm{S} / \mathrm{N}$ ratio for each level of the factors $\mathrm{A}, \mathrm{B}$ and $\mathrm{C}$ is summarized and called the $\mathrm{S} / \mathrm{N}$ response table for roughness (Table 4).

Table 4 Response table of mean $\mathrm{S} / \mathrm{N}$ ratio

\begin{tabular}{|c|c|c|c|}
\hline Level & A & B & C \\
\hline 1 & 8.0489 & 7.2594 & 8.6226 \\
\hline 2 & 7.1377 & 7.9106 & 7.1356 \\
\hline 3 & 8.3355 & 8.3524 & 7.7639 \\
\hline Rank & 2 & 3 & 1 \\
\hline Delta & 1.1978 & 1.0930 & 1.4869 \\
\hline
\end{tabular}

The total mean $\mathrm{S} / \mathrm{N}$ ratio $=14.79 \mathrm{~dB}$

The corresponding main effects and interaction effects plots between the process parameters are also shown in Figs. 1 and 2 respectively. In the main effects plot if the line for particular parameter is near horizontal, then the parameter has no significant effect. On the other hand, a parameter for which the line has the highest inclination will have the most significant effect. It is very much clear from the main effects plot that parameter $\mathrm{C}$ (concentration of nickel source solution) is the most significant parameter while parameter A (bath temperature) has also got some significant effect. So far as the interaction plots are concerned, estimating an interaction means determining the non-parallelism of parameter effects. Thus, if the lines on the interaction plots are non-parallel, interaction occurs and if the lines cross, strong interactions occur between parameters. Fig. 2 reveals there is strong interaction between the parameters $\mathrm{A}$ and $\mathrm{B}$ while there is moderate interaction between the parameters A and $\mathrm{C}$. Thus from the present analysis it is clear that the concentration of nickel source solution (C) is the most influencing parameter for $R_{a}$ of EN coatings. The optimal process parameter combination for minimum roughness is found to be $\mathrm{A} 3 \mathrm{~B} 3 \mathrm{C} 1$. It may be considered at this point that the concentration of $\mathrm{Ni}$ deposited at a point on the surface is related to the depletion of $\mathrm{Ni}$ in the solution in a half sphere around that point. The mobility of the molecules in the solution is also determined by the bath temperature (parameter $\mathrm{A}$ ). Also the factors $\mathrm{A} \times \mathrm{B}$ and $\mathrm{A} \times \mathrm{C}$ relate in some way to the mobility of the molecules in solution since both theses interaction factors contain the factor $\mathrm{A}$.

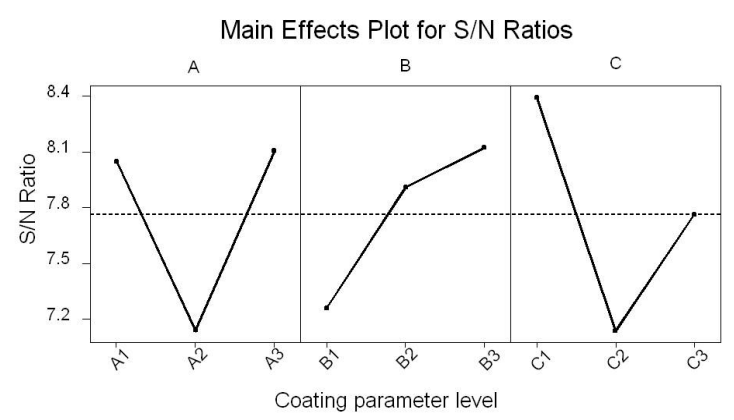

Fig. 1 Main effects plot for signal to noise ratio
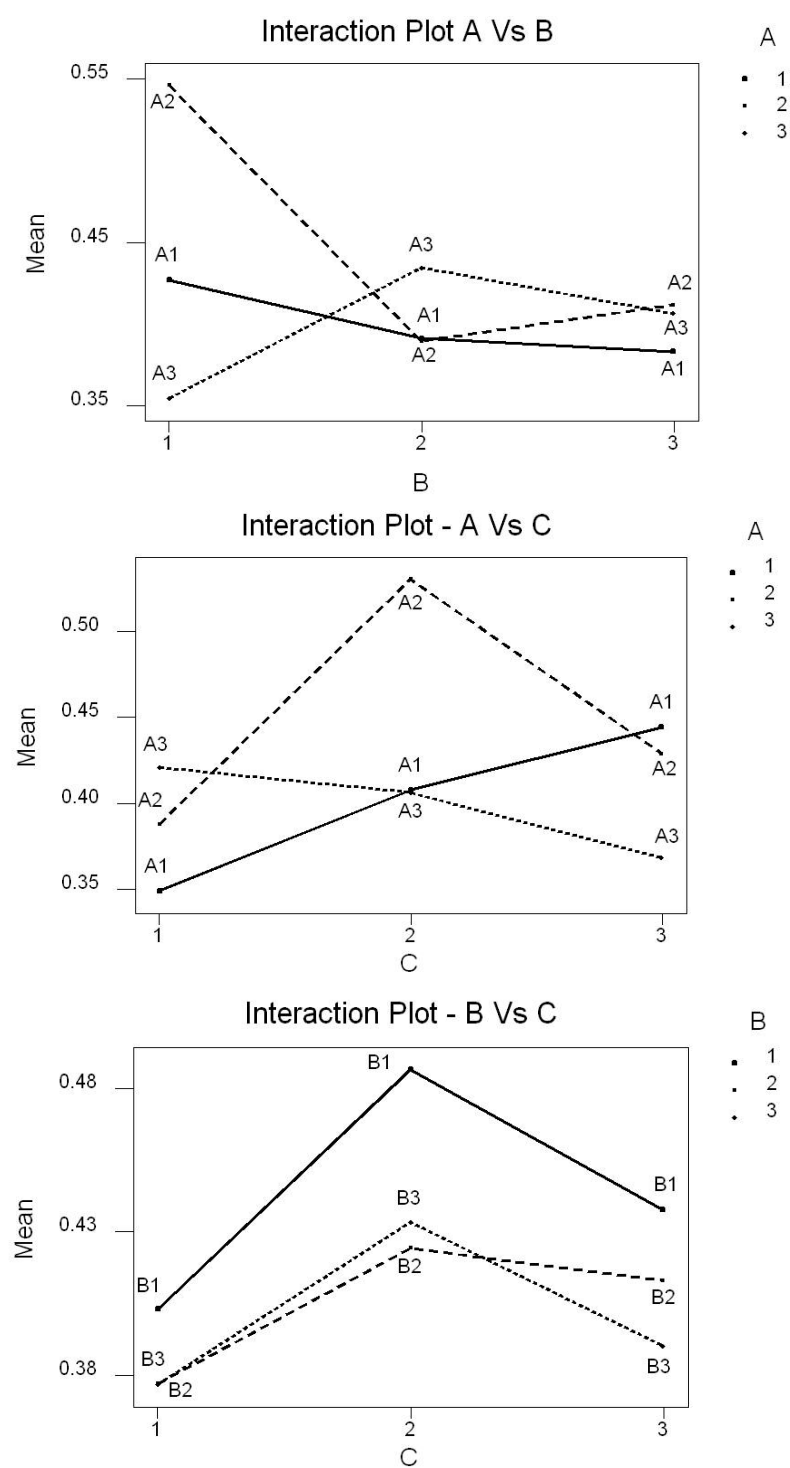

Fig. 2 Interaction effect plots for mean $\mathrm{S} / \mathrm{N}$ ratios 


\subsection{Analysis of variance (ANOVA)}

Using Minitab ${ }^{22}$, ANOVA is performed to determine which parameter and interaction significantly affect the performance characteristics. Table 5 shows the ANOVA result for $R_{a}$ of EN coatings. ANOVA calculates the $F$-ratio, which is the ratio between the regression mean square and the mean square error. This ratio is used to measure the significance of the parameters under investigation with respect to the variance of all the terms included in the error term at the desired significance level, $\alpha$. If the calculated value of $F$-ratio is higher than the tabulated value of $F$-ratio, then the factor is significant at desired $\alpha$ level. ANOVA table shows the percentage contribution of each parameter. It is seen that parameter $C$, i.e. concentration of nickel source solution has got the most significant influence on roughness at the confidence level of $75 \%$ while parameter A (bath temperature) has got some influence within the specific test range. Similarly, the interaction of parameters $\mathrm{A} \times \mathrm{B}$ has got strong influence on roughness while interaction $\mathrm{A} \times \mathrm{C}$ has got some contribution.

Table 5 Results of ANOVA

\begin{tabular}{|c|c|c|c|c|c|}
\hline Source & $\begin{array}{l}\text { Degrees } \\
\text { of } \\
\text { freedom }\end{array}$ & $\begin{array}{c}\text { Sum of } \\
\text { squares }\end{array}$ & $\begin{array}{c}\text { Mean } \\
\text { square }\end{array}$ & $F$ & $\begin{array}{c}\text { \%Contri- } \\
\text { bution }\end{array}$ \\
\hline $\mathrm{A}$ & 2 & 7.043 & 3.521 & $1.81^{*}$ & 10 \\
\hline $\mathrm{B}$ & 2 & 5.442 & 2.721 & 1.40 & 8 \\
\hline $\mathrm{C}$ & 2 & 10.033 & 5.017 & $2.58^{*}$ & 16 \\
\hline $\mathrm{A} \times \mathrm{B}$ & 4 & 16.569 & 4.142 & $2.13^{*}$ & 26 \\
\hline $\mathrm{A} \times \mathrm{C}$ & 4 & 9.461 & 2.365 & 1.22 & 15 \\
\hline $\mathrm{B} \times \mathrm{C}$ & 4 & 0.589 & 0.147 & 0.08 & 1 \\
\hline Error & 8 & 15.559 & 1.945 & & 24 \\
\hline Total & 26 & 64.696 & & & 100 \\
\hline
\end{tabular}

Table 6 Results of confirmation test

\begin{tabular}{|c|c|c|c|}
\hline & \multirow{2}{*}{$\begin{array}{c}\text { Initial } \\
\text { parameter } \\
\text { combination }\end{array}$} & \multicolumn{2}{|c|}{$\begin{array}{c}\text { Optimal parameter } \\
\text { combination }\end{array}$} \\
\cline { 3 - 4 } & & Prediction & Experimentation \\
\hline Level & $\mathrm{A} 2 \mathrm{~B} 2 \mathrm{C} 2$ & \multicolumn{2}{|c|}{ A3B3C1 } \\
\hline$R_{a}(\mu \mathrm{m})$ & 0.419 & & 0.315 \\
& & & 10.0283 \\
\hline $\mathrm{S} / \mathrm{N}$ Ratio & 7.5454 & 8.5600 & $\mathrm{~dB}$ \\
\hline
\end{tabular}

\subsection{Confirmation test}

After the optimal level of process parameters has been found out, a verification test needs to be carried out in order to check the accuracy of analysis. The estimated $\mathrm{S} / \mathrm{N}$ ratio, $\hat{\gamma}$, using the optimal level of the process parameters can be calculated as:

$\hat{\gamma}=\gamma_{m}+\sum_{i=1}^{o}\left(\bar{\gamma}_{i}-\gamma_{m}\right)$ where $\gamma_{m}$ is the total mean $\mathrm{S} / \mathrm{N}$ ratio, $\bar{\gamma}_{i}$ is the mean $\mathrm{S} / \mathrm{N}$ ratio at the optimal level, and o is the number of the main design parameters that significantly affect the roughness of electroless Ni-P coating. Table 6 shows the comparison of the estimated $\mathrm{S} / \mathrm{N}$ ratio with the actual $\mathrm{S} / \mathrm{N}$ ratio using the optimal parameters. The increase of the $\mathrm{S} / \mathrm{N}$ ratio from the initial coating parameters to the optimal coating parameters is $2.4829 \mathrm{~dB}$, which means roughness is reduced by about $25 \%$.

\subsection{Surface morphology and composition}

Fig. 3 shows the SEM micrographs of the coating surfaces as-deposited as well as heat treated at $400^{\circ} \mathrm{C}$. It is seen that there are many globular particles on the surface of the substrate. The surface is optically smooth and of low porosity. No obvious surface damage is found. The surface of the Ni-P coatings appears to be dense. The XRD analysis (Fig. 4) indicates that the as-deposited Ni-P film is a mixture of nanocrystalline (uniformly spaced grain structure), microcrystalline phases. When Ni-P deposits are heat treated, the microcrystalline deposits undergo a crystal growth process and results in a mixture of relatively coarse-grained structure.

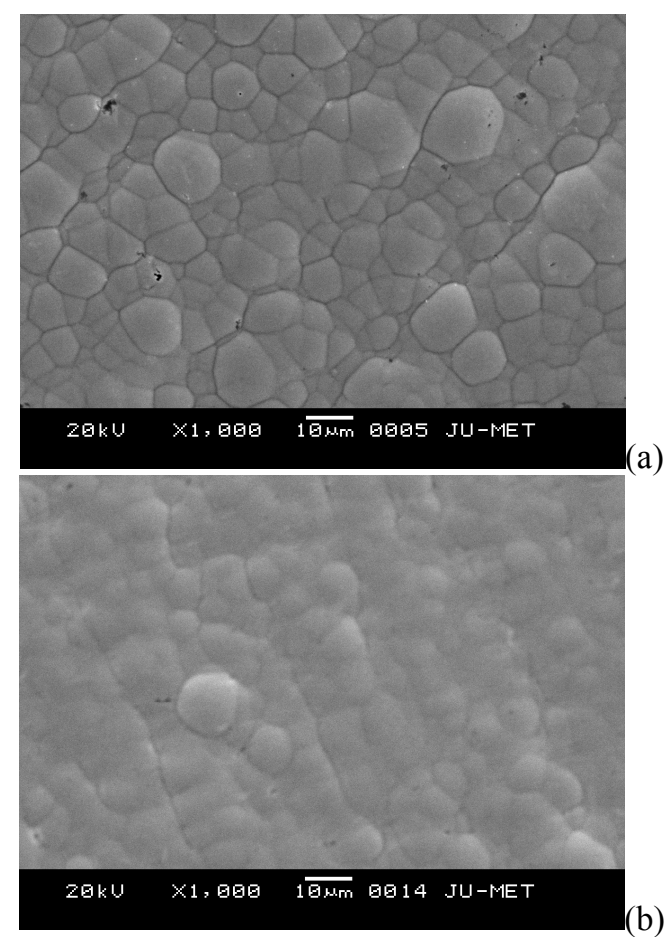

Fig. 3 SEM micrographs: (a) as deposited, (b) heat treated at $400^{\circ} \mathrm{C}$

The EDX analysis shows that as-deposited coating contains $88.6 \% \mathrm{Ni}$ and $11.4 \% \mathrm{P}$ while heat-treated (at $400^{\circ} \mathrm{C}$ ) coatings have $90.8 \% \mathrm{Ni}$ and $9.2 \% \mathrm{P}$. Thus the coatings contain more than $9 \%$ of phosphorous leading to a nanocrystalline structure. It is evident from the XRD patterns in Fig. 4(a) that Ni-P deposit is nanocrystalline in as-plated condition. There is long range order giving rise to coherent scattering, although 
the domains are small in size. The mean grain size is of the order of $2 \mathrm{~nm}$. Upon heat treatment at $400^{\circ} \mathrm{C}$, Ni-P deposits crystallize and produce $\mathrm{Ni}_{5} \mathrm{P}_{2}, \mathrm{Ni}_{2} \mathrm{P}$ and $\mathrm{NiP}_{2}$ as major compound constituents as seen in Fig. 4(b).

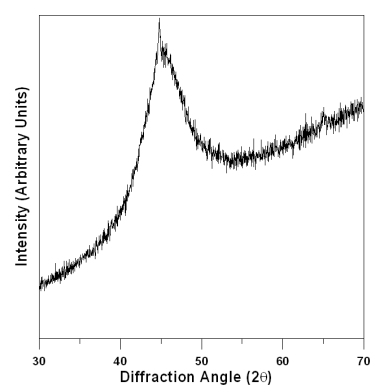

(a)

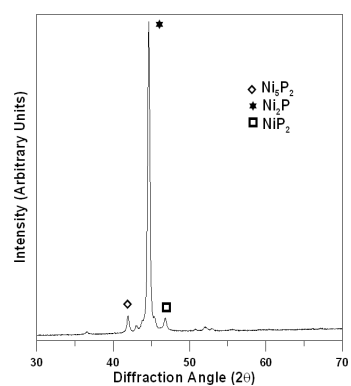

(b)
Fig. 4 XRD patterns of EN coatings: (a) as deposited and (b) heat treated at $400^{\circ} \mathrm{C}$.

\section{Conclusions}

Taguchi orthogonal array is employed to optimize the coating process parameters with respect to roughness of electroless Ni-P coatings. It is seen that concentration of nickel source solution (C) has got the most significant influence while parameter A (bath temperature) has some influence within the specific test range. Similarly, the interaction of bath temperature with source of reducing agent $(\mathrm{A} \times \mathrm{B})$ have got strong influence on roughness of the coating while interaction of bath temperature with concentration of nickel source $(\mathrm{A} \times \mathrm{C})$ has got some contribution. The optimal coating parameter combination for minimum roughness is obtained as $\mathrm{A} 3 \mathrm{~B} 3 \mathrm{C} 1$ and the roughness is reduced by about $25 \%$ from initial to optimal process parameter condition. The XRD analysis indicates that the as-deposited Ni-P film consists of a mixture of nanocrystalline (uniformly spaced grain structure), microcrystalline phases. Heat treatment results in a relatively coarse-grained structure. The EDX analysis shows that the films contain more than $9 \%$ of phosphorous resulting in a nanocrystalline structure.

\section{References}

[1] Brenner, A. and Riddell, G. E., Nickel Plating by Chemical Reduction, US Patent US2532282, 1950.

[2] Riedel, W., Electroless Nickel Plating, Finishing Publications Ltd., Warrington, 1991.

[3] Allen, R. M. and Vandersande, J. B., "The Structure of Electroless Ni-P Films as a Function of Composition," Scripta Metall., 16, 10, 1982, 1161-1164.

[4] Berkh, O., Eskin, S. and Zahavi, J., "Properties of Electrodeposited NiP-SiC Composite Coatings," Metal Finishing, 94, 1996, 35-40.

[5] Baudrand, D. and Bengston, J., "Electroless Plating Processes: Developing Technologies for
Electroless Nickel, Palladium, and Gold," Metal Finishing, 93, 9, 1995, 55-57.

[6] Agarwala, R. C. and Agarwala, V., "Electroless Alloy/Composite Coatings: a Review," Sadhana, 28, 3-4, 2003, 475-493.

[7] Hur, K. H., Jeong, J. H. and Lee, D. N., "Microstructures and Crystallization of Electroless Ni-P Deposits," J. Mater. Sci., 25, 5, 1990, 2573-2584.

[8] Apachitei, I., Duszczyk, J., Katgerman, L. and Overkamp, P. J. B., "Electroless Ni-P Composite Coatings: the Effect of Heat Treatment on the Micro-Hardness of Substrate and Coating," Scripta Mater., 38, 9, 1988, 1347-1353.

[9] Huang, Y. S., Zeng, X. T., Annergren, I. and Liu, F. M., "Development of Electroless Ni-P-PTFE-SiC Composite Coating," Surf. Coat. Technol., 167, 2003, 207-211.

[10] Straffelini, G., Colombo, D. and Molinari, A., "Surface Durability of Electroless Ni-P Composite Deposits," Wear, 236, 1999, 179-188.

[11] Zhao, Q., Liu, Y., Muller-Steinhagen, H. and Liu, G., "Graded Ni-P-PTFE Coatings and Their Potential Applications," Surf. Coat. Technol., 155, 2002, 279-284.

[12] Staia, M. H., Castillo, E. J., Puchi, E. S., Lewis, B. and Hintermann, H. E., "Wear Performance and Mechanism of Electroless Ni-P Coating," Surf. Coat. Technol., 86-87, 1996, 598-602.

[13] Staia, M. H., Enriquez, C. and Puchi, E. S., "Influence of the Heat Treatment on the Abrasive Wear Resistance of Electroless Ni-P," Surf. Coat. Technol., 94-95, 1997, 543-548.

[14] Taheri, R., Oguocha, I. N. A. and Yannacopoulos, S., "The Tribological Characteristics of Electroless Ni-P Coatings," Wear, 249, 2001, 389-396.

[15] Quercia, G., Grigoresu, I., Contreras, H., Rauso, C. D. and Gutierrez-Campos, D., "Friction and Wear Behavior of Several Hard Materials," Int. J. Refractory Metals \& Hard Materials, 19, 2001, 359-369.

[16] Ramalho, A. and Miranda, J. C., "Friction and Wear of Electroless Ni-P and Ni-P + PTFE Coatings," Wear, 259, 2005, 828-834.

[17] Alirezaei, S., Monirvaghefi, S. M., Salehi, M. and Saatchi, A., "Wear Behavior of Ni-P and Ni-P$\mathrm{Al}_{2} \mathrm{O}_{3}$ Electroless Coatings," Wear, 262, 7-8, 2007, 978-985.

[18] Taguchi, G., Introduction to Quality Engineering, Asian Productivity Organization, 1990.

[19] Ross, P. J., Taguchi Techniques for Quality Engineering (2e), McGraw-Hill, New York, 1996.

[20] Montgomery, D. C., Design and Analysis of Experiments, Wiley, New York, 2001.

[21] Minitab User Manual (Release 13.2), Making Data Analysis Easier, MINITAB Inc, State College, PA, USA, 2001. 